\title{
Trabajadores pobres en Argentina y en España: un análisis comparativo centrado en las desigualdades ocupacionales
}

\section{Santiago Poy}

Universidad Católica Argentina, CONICET, Observatorio de la Deuda Social Argentina.

Ciudad Autónoma de Buenos Aires, Argentina.

santiago_poy@uca.edu.ar

\section{Resumen}

El artículo aborda la relación entre los procesos de estratificación económico-ocupacional y la pobreza laboral (in-work poverty) a partir de un enfoque comparativo entre Argentina y España. Sin desconocer los múltiples determinantes de la pobreza laboral, la principal hipótesis es que la estratificación del mercado de trabajo tiene un rol explicativo fundamental y que, incluso en contextos nacionales distintos, puede identificarse una pauta similar de estructuración de la probabilidad de experimentarla, ligada a clivajes ocupacionales. Se elaboró una tipología de posiciones económico-ocupacionales, se implementó un análisis descriptivo del perfil de estratificación de ambos países y se llevaron adelante modelos de regresión logística sobre dos definiciones de la pobreza laboral: la individual y la del hogar. La investigación se sustentó en los microdatos de la Encuesta Permanente de Hogares (Argentina) y de la Encuesta de Condiciones de Vida (España). Los resultados exhiben importantes diferencias en el perfil de estratificación entre Argentina y España. Sin embargo, en línea con la hipótesis, también se evidencia que en ambos países la posición económico-ocupacional es un determinante fundamental de la pobreza laboral —a igualdad de características individuales o familiares- y que los mismos grupos de trabajadores (asalariados precarios y de microempresas, y trabajadores por cuenta propia de baja cualificación) concentran las mayores oportunidades relativas de ser pobres, sea cual sea la definición adoptada.

Palabras clave: pobreza laboral; segmentación del mercado de trabajo; análisis comparativo 
Abstract. Working poor in Argentina and Spain: A Comparative Analysis Focused on Labour Market Inequalities

The article tackles the relationship between labour market stratification and in-work poverty, through a comparative analysis of Argentina and Spain. Although it is usual to refer to its multiple determinants, the main hypothesis is that the labour market's stratification plays a fundamental explanatory role on in-work poverty and that, even in different countries, a similar pattern, linked to labour market inequalities, can be identified. The paper draws on the construction of a typology of economic-occupational positions, performs a descriptive analysis of the labour market stratification and carry out binomial logistic regression models, using two different definitions of in-work poverty, both at the individual and the household's level. The research relies on the Permanent Household Survey (Argentina) and the Survey of Living Conditions (Spain) microdata. The results show important differences in labour market's stratification in Argentina and Spain. However, as the hypotheses states, the economic-occupational position is a fundamental determinant of in-work poverty in both countries — ceteris paribus individual or households' characteristics - and that the same groups of workers (precarious and microenterprises' wage earners and lowskilled self-employed workers) concentrate the greatest odds ratios of poverty, whatever the definition adopted.

Keywords: in-work poverty; labour market segmentation; comparative analysis

\section{Sumario}

1. Introducción 5. Conclusiones

2. Perspectiva teórica Agradecimientos

3. Fuentes de datos y metodología Financiación

4. Resultados Referencias bibliográficas

\section{Introducción}

Las transformaciones de los mercados de trabajo durante las décadas recientes plantean numerosos desafíos para la equidad y la cohesión social. La expansión de formas de empleo desprotegidas y precarias reestructura las desigualdades socioocupacionales e introduce nuevas dimensiones a la segmentación laboral (Grimshaw et al., 2017). En este contexto, el objetivo del «trabajo decente» (ILO, 1999) enfrenta múltiples obstáculos. Una de sus expresiones es la persistencia de trabajadores pobres (working poor), es decir, personas que viven en pobreza pese a encontrarse ocupadas. El concepto expresa los límites del trabajo como mecanismo de integración y garantía frente a la exclusión social. Si bien se han registrado progresos en las últimas décadas, 700 millones de trabajadores de todo el mundo viven en pobreza extrema o moderada (ILO, 2019).

A partir de un enfoque comparativo, el objetivo de este artículo es examinar la relación entre los procesos de estratificación económico-ocupacional y la pobreza laboral (in-work poverty) en dos contextos socioeconómicos e institucionales diferentes: Argentina y España. Específicamente, los interrogantes que 
orientaron la investigación fueron los siguientes. ¿Cómo influye la posición económico-ocupacional en la probabilidad de experimentar pobreza laboral en ambos países? ¿Es posible identificar un patrón similar de oportunidades relativas, ligadas a clivajes económico-ocupacionales, con respecto a la probabilidad de experimentar pobreza laboral? Mediante el tratamiento de este objetivo, el artículo se propone contribuir al estudio de los procesos que organizan la desigualdad sociolaboral e impactan sobre el bienestar y la vulnerabilidad de distintos grupos de trabajadores. ${ }^{1}$

En los últimos años, los países europeos experimentaron una recuperación económica y del empleo tras la gran recesión (Comisión Europea, 2019). Un rasgo clave de esta recuperación ha sido la baja calidad de los puestos creados, en particular, en países como España, Francia e Italia (ILO, 2019). La salida de la crisis ha coexistido con la persistencia de una proporción significativa de trabajadores que se encuentran en situación de pobreza o en riesgo de exclusión social pese a estar ocupados (Banyuls y Recio, 2017a). ${ }^{2}$ En América Latina, a pesar del fuerte crecimiento registrado durante casi una década y de la implementación de activas políticas laborales y distributivas, alrededor de la mitad de la fuerza de trabajo tiene ocupaciones de baja calidad, sin acceso a la seguridad social o en actividades de muy baja productividad (ILO, 2018). A su vez, la persistencia de cifras elevadas de pobreza constituye uno de los principales desafíos de la actual agenda social (CEPAL, 2019). ${ }^{3}$

La cuestión de los trabajadores pobres abre una oportunidad para el análisis comparado de las desigualdades sociolaborales en el norte y en el sur globales y de sus implicancias en términos de bienestar y exclusión social. En Europa, el creciente interés académico por este fenómeno se comprende a la luz de las mutaciones recientes de los mercados laborales (Lohmann y Crettaz, 2018). Si era habitual considerar que el acceso al empleo protegía frente a la pobreza, en la actualidad se admite que esta relación no puede darse por descontada (Filandri y Struffolino, 2019). En América Latina, la reflexión sobre el vínculo entre las características de los mercados de trabajo y la pobreza ha sido recurrente durante las últimas siete décadas. En contextos de insuficiente demanda laboral y seguros de desempleo limitados, muchos trabajadores deben generar ocupaciones de baja productividad o de subsistencia (a menudo en el marco de estrategias familiares) para proveerse de ingresos (ILO, 2018; Tokman, 2006). La constatación de situaciones de pobreza persistente y extendida originó numerosas contribuciones académicas orientadas a dilucidar su relación

1. Recientemente se han realizado análisis comparativos entre Europa y América Latina desde un enfoque centrado en las desigualdades laborales (López-Roldán y Fachelli, 2019; Semenza y Sarti, 2018).

2. De acuerdo con datos de Eurostat, el 9,6 \% de los trabajadores ocupados vivían en hogares pobres hacia 2016. La incidencia presentaba importantes divergencias nacionales: alcanzaba al $18,9 \%$ de los trabajadores en Rumania y a apenas al 3,1 \% en Finlandia.

3. En efecto, según la Comisión Económica para América Latina (CEPAL, 2019), en 2018 alrededor del 29,6 \% de la población latinoamericana era pobre por ingresos, sin cambios sustantivos desde 2012 . 
con las actividades laborales predominantes en la región (Pérez-Sáinz y MoraSalas, 2006).

La literatura reconoce una multiplicidad de factores económicos, institucionales, familiares e individuales asociados a la pobreza laboral, que abarcan desde el nivel de desarrollo económico y los sistemas de bienestar hasta la composición sociodemográfica de los hogares (Lohmann, 2018; Lohmann y Crettaz, 2018; Thiede, Sanders y Lichter, 2018). Sin desconocer la incidencia de los numerosos factores reconocidos, este artículo se enfoca en el papel desempeñado por los atributos de los puestos de trabajo. Pretende contribuir así a las investigaciones que ligan la pobreza laboral con la desigualdad en el mercado de trabajo (Banyuls y Recio, 2017a; Filandri y Struffolino, 2019; Horemans et al., 2016; Halleröd et al., 2015; Maître et al., 2012; Maurizio, 2018; Salverda, 2018). A partir de una comprensión estructural de la pobreza, ${ }^{4}$ se explora la hipótesis general de que la estratificación del mercado de trabajo tiene un rol explicativo fundamental en la pobreza laboral y que incluso en contextos nacionales distintos puede identificarse una pauta de estructuración similar de la probabilidad de experimentarla, ligada a clivajes ocupacionales. De esta manera, los procesos de estratificación y segmentación del mercado de trabajo tendrían un papel clave incluso en presencia de distintas condiciones sociodemográficas, individuales o familiares de los trabajadores.

En general, el estudio de los trabajadores pobres se ha concentrado en casos nacionales, en la comparación entre países con similares niveles de desarrollo o que pertenecen a las mismas regiones geográficas o mercados comunes (Brady et al., 2010; 2013; Crettaz, 2013; Filandri y Struffolino, 2019; Halleröd et al., 2015; Lohmann, 2009; Maurizio, 2018). Este artículo contribuye a la literatura existente al proponer un examen comparativo de dos «sistemas nacionales» diferentes (Caïs, 1997). Se trata de un estudio cross-national en el cual los países son contextos de estudio de objetos complejos (Piovani y Krawczyk, 2017); por lo tanto, la comparación se propone enriquecer el alcance analítico y empírico de un enfoque teórico. A los fines de esta investigación, cabe mencionar dos ejes en torno a los cuales advertir diferencias y similitudes entre Argentina y España: el desarrollo económico y la regulación del mercado de trabajo.

En términos de sus procesos de desarrollo económico, Argentina y España son países de industrialización tardía que habían logrado una rápida expansión del sector industrial y de servicios hacia mediados de los años setenta (Ishida y Miwa, 2011, en López-Roldán y Fachelli, 2019: 164). La estructura productiva de ambos países guarda algunas semejanzas: hay un significativo predominio del sector de servicios (dos tercios de sus respectivos PIB se explican por tales actividades), una alta incidencia de microempresas o de empresas pequeñas, una tendencia al uso intensivo de fuerza de trabajo y una

4. Según Brady (2019), pueden diferenciarse tres enfoques sobre la pobreza: los comportamentales, los políticos y los estructurales. De acuerdo con este último - que es el que adoptamos aquí-, se enfatiza en determinantes estructurales como el tipo y el ritmo de crecimiento económico o el nivel de desarrollo, más que en las características de las personas pobres. 
escasez de firmas que utilicen tecnología de punta (Banyuls y Recio, 2017b; Banyuls et al., 2009; López-Roldán y Fachelli, 2019; Salvia et al., 2018). A pesar de estas similitudes, las diferencias en el nivel de desarrollo de Argentina y España son ostensibles: si hasta mediados de los sesenta ambos países se asemejaban, el producto interior bruto (PIB) per cápita español de 2017 -en dólares a paridad de poder adquisitivo (PPA) — duplicaba al argentino. Se trata de una diferencia clave por sus implicancias sobre el bienestar y la pobreza absoluta.

También existen diferencias importantes en las formas de regulación del mercado de trabajo. El modelo del mercado de trabajo español, que algunos autores caracterizan como «neoliberal mediterráneo» (Banyuls et al., 2009; López-Roldán y Fachelli, 2019), se caracteriza por sus altas tasas de desempleo, la extensión de formas de contratación temporarias y flexibles y las trayectorias laborales inestables (Verd y López Andreu, 2016). De todas formas, España cuenta con un sistema de regulación del desempleo —el seguro de paro- ampliamente extendido y que garantiza la sustitución de ingresos a los trabajadores desocupados. Este sistema suele estar muy poco difundido en los países periféricos y, además, reporta rentas muy exiguas (Tokman, 2006). El mercado de trabajo argentino, a su vez, se caracteriza por una fuerte regulación, estructurada alrededor de una ley de contrato de trabajo que promueve el empleo estable y permanente, y con altos niveles de sindicalización (Bertranou y Casanova, 2015). Sin embargo, con una escasa difusión de las contrataciones temporarias, este modelo altamente regulado coexiste con otra fracción del mercado laboral —que involucra alrededor del $50 \%$ de la fuerza de trabajo (Donza, 2019) — que opera en condiciones irregulares, eludiendo las normativas laborales y sin contrato (Poy, 2017; Salvia et al., 2018).

El artículo se estructura de la siguiente manera. La primera sección presenta la perspectiva teórica. La segunda desarrolla la metodología y las fuentes de datos empleadas para el análisis comparativo. La tercera sección expone los resultados a partir de una aproximación descriptiva y la utilización de modelos multivariantes de regresión logística sobre los determinantes de la pobreza laboral. Por último, la cuarta sección plantea las reflexiones finales.

\section{Perspectiva teórica}

Si bien los estudios sobre pobreza y desigualdad siempre enfatizaron su relación con la dinámica ocupacional, el concepto de pobreza laboral es relativamente reciente (Lohmann, 2018). Su difusión se relaciona con los cambios en los mercados de trabajo y en la política laboral durante los últimos años, con la crisis económica mundial y el aumento de la desigualdad de los ingresos laborales (Fraser et al., 2011). Se trata de un concepto «híbrido», pues combina el análisis del mercado de trabajo con el estudio de la pobreza.

El concepto de pobreza puede involucrar múltiples significados, aunque en general se aborda desde dos perspectivas analíticas. En primer lugar, según un enfoque absoluto, la pobreza es entendida como la carencia de recursos 
suficientes para el sostenimiento de la vida. Desde este enfoque, en general, la pobreza se asocia con la imposibilidad de satisfacer una serie de necesidades básicas ligadas a la supervivencia material (Feres y Mancero, 2001). En segundo lugar, de acuerdo con un enfoque relativo, las personas pobres son aquellas que no logran acceder a un estándar de vida aceptable para la sociedad en la que viven (Spicker, 2007). En general, en los países de menor desarrollo económico se emplea una medición absoluta de la pobreza, y en los países desarrollados se utilizan medidas relativas.

En el tratamiento de la pobreza laboral, Filandri y Struffolino (2019) también identifican dos aproximaciones. Desde una perspectiva individual, se entiende como trabajadores pobres a aquellos ocupados cuyos ingresos son inferiores a un cierto umbral. Esta definición se emparenta con la noción más habitual de "trabajadores de bajos ingresos» (low pay workers) (Maître, et al., 2012). En segundo lugar, desde un enfoque centrado en el ámbito del hogar se define a los trabajadores pobres como aquellos ocupados que viven en hogares pobres (Fraser et al., 2011; Halleröd et al., 2015; Lohmann, 2018). Algunos estudios sugieren que el solapamiento entre ambas definiciones resulta acotado en términos empíricos. Por las características sociodemográficas del hogar y por los comportamientos laborales del resto de los integrantes, algunos trabajadores que no son pobres viven en hogares que sí lo son y viceversa (Lohmann, 2018; Maître et al., 2012). El fuerte crecimiento de la participación laboral femenina y el declive del modelo de proveedor único (male bread winner), junto con los cambios demográficos de las familias, vuelven comprensible esta discrepancia. En este artículo decidimos no circunscribir el concepto de pobreza laboral a una única aproximación, pues ambas perspectivas pueden ofrecer evidencias complementarias en un estudio comparativo. Entendemos que la pobreza laboral involucra a los «trabajadores pobres» y a los «trabajadores en hogares pobres». 5

El carácter híbrido del concepto de pobreza laboral se plasma en la naturaleza multidimensional de los enfoques teóricos que buscan explicarlo. Tales explicaciones a menudo abarcan factores institucionales, características individuales y familiares de los trabajadores y atributos de los puestos de trabajo (Crettaz, 2013; Lohmann, 2009; Lohmann y Crettaz, 2018). Este artículo se centra en uno de estos ejes: la relación entre las formas de inserción económicoocupacional (que remite a la estratificación del mercado de trabajo) y la pobreza laboral. Para tematizar la desigualdad ocupacional, se recogen los aportes clásicos de las teorías de la segmentación que describen la estratificación de los mercados de trabajo y contribuciones latinoamericanas que han procurado ligar los procesos de segmentación con características económicas más generales,

5. El análisis de la pobreza laboral en el ámbito del hogar implica asumir el supuesto de que todos los integrantes aportan el conjunto de sus ingresos al presupuesto compartido. La investigación empírica revela que este supuesto solo se cumple parcialmente y que en los hogares existen distintas maneras de compartir ingresos (pooling regimes) (Ponthieux, 2013). Las decisiones sobre la distribución de recursos económicos dentro de los hogares están atravesadas por clivajes socioculturales, de género y generación (Jelin, 2010). 
como la heterogeneidad estructural o las brechas tecnológicas entre empresas y sectores de actividad. ${ }^{6}$

Las teorías sobre la segmentación discuten la concepción neoclásica ortodoxa según la cual el mercado de trabajo es homogéneo con respecto a la asignación de puestos y remuneraciones y, en ausencia de perturbaciones institucionales, tiende al equilibrio (Fernández-Huerga, 2010). Se argumenta que existen diferentes segmentos laborales con puestos de trabajo de distinta calidad (Neffa, 2008). En el plano microeconómico, la perspectiva iniciada por Doeringer y Piore (1971) se enfoca en la existencia de mercados «internos» y «externos» a las empresas. En el macroeconómico, se describe la existencia de posiciones jerarquizadas en los mercados de trabajo (López-Roldán et al., 1998) y una estructura tripartita: un segmento "primario superior» e «inferior», con puestos estables, remuneraciones adecuadas y posibilidades de ascenso, y un segmento «secundario», de puestos de baja calidad y remuneración (Piore, 1972). ${ }^{7}$ Los economistas radicales sumaron dos elementos a esta descripción: por un lado, argumentaron que la segmentación constituía una estrategia empresarial para debilitar a los trabajadores; por otro lado, se enfocaron en la correlación entre los segmentos del mercado y ciertos perfiles de trabajadores, atendiendo a clivajes como el género, el origen migratorio o la etnia (Reich et al., 1973).

Los aportes teóricos recientes sobre la segmentación del mercado de trabajo señalan que las transformaciones económicas y productivas de las últimas décadas, alentadas por la globalización, propician la reestructuración de las desigualdades laborales. Las estrategias empresariales dominantes en este escenario globalizado, así como las políticas laborales y de bienestar implementadas para favorecer la competitividad en este contexto, habrían favorecido la expansión de formas de contratación inestables y precarias (Grimshaw et al., 2017). La articulación de transformaciones socioeconómicas e institucionales genera nuevas desigualdades en el acceso a ocupaciones protegidas, expone a una parte de la fuerza de trabajo a la vulnerabilidad y agrega nuevas dimensiones a la fragmentación del mercado de trabajo (Rubery, 2015).

Retomamos en este punto los aportes teóricos de la perspectiva estructuralista latinoamericana que procuraron relacionar los procesos de segmentación del mercado laboral con las características de los sistemas productivos y de las unidades económicas predominantes. En América Latina, la conceptualización de la segmentación de los mercados de trabajo está ligada a los estudios sobre la «informalidad» (PREALC, 1978). Una característica de los mercados laborales de estos países es la existencia de una oferta de fuerza de trabajo «excedente» para la demanda capitalista en las condiciones de desarrollo vigentes (Cortés,

6. Una serie de investigaciones han abordado la cuestión de la segmentación en España (Banyuls y Recio, 2017b; López Roldán et al., 1998; Recio, 1991; entre otros) y en Argentina (Bertranou et al., 2014; Paz, 2013; Poy, 2017; Salvia y Vera, 2013).

7. Los puestos del segmento primario superior se caracterizarían por su perfil profesional frente a los puestos estables pero rutinarios del segmento primario inferior (Osterman, 1984). Piore (1972) señala que la segmentación laboral coincide así con una distinción más general entre clase media, clase trabajadora y clase baja. 
2000; Pérez-Sáinz y Mora-Salas, 2006; PREALC, 1978). Este rasgo adquiere una manifestación distintiva en los menores niveles de asalarización en los países periféricos en comparación con los desarrollados, ${ }^{8}$ que son la contracara de la proliferación de actividades laborales de muy baja productividad ligadas al autoempleo y a las estrategias familiares de subsistencia (Tokman, 2006). Este conjunto de actividades económicas de subsistencia ha sido referido como «sector informal», por contraposición al sector dinámico o «moderno» de empresas de mayor productividad (Gasparini y Tornarolli, 2009; Husmanns, 2004). ${ }^{9}$ $\mathrm{Al}$ enfocarse principalmente en la fuerza de trabajo asalariada, las perspectivas habituales sobre la segmentación no suelen tomar en cuenta esta especificidad de la estratificación de los mercados laborales periféricos.

A su vez, la perspectiva estructuralista enfatiza el papel de las asimetrías productivas tecnológicas entre empresas y ramas en la estratificación del mercado laboral. Un rasgo reseñado con frecuencia por la literatura sobre el desarrollo económico se refiere a las asimetrías productivas que existen en los países periféricos en comparación con los avanzados (Infante, 2011). Esta característica ha sido extensamente tratada en la tesis de la "heterogeneidad estructural» (Pinto, 1970), que alude a la coexistencia de actividades en las cuales la productividad media del trabajo es próxima a la de la frontera internacional junto con actividades rezagadas cuyos niveles de productividad son muy reducidos (Rodríguez, 2001). Las brechas de productividad sectoriales afectan a todas las economías de mercado — tal como señalaron tempranamente Nohlen y Sturm (1982)—, pero las discontinuidades se hacen más ostensibles en los países menos desarrollados (Infante, 2011). Con respecto al mercado de trabajo, el estrato de productividad al que pertenecen las unidades económicas es determinante del tipo de puestos (en términos de calidad, estabilidad y retribución) al que acceden los trabajadores (Tokman, 2006). ${ }^{10}$ Los antecedentes para Argentina y España previamente referidos señalan la relevancia que adquieren en ambos países las asimetrías de productividad entre empresas y la importancia de las microempresas como empleadoras de fuerza de trabajo. Por consiguiente, cabe argumentar que tales características deben desempeñar un papel relevante en la estratificación del mercado de trabajo de los países bajo estudio.

El enfoque conceptual desarrollado hasta aquí permite formular la hipótesis de que la estratificación del mercado de trabajo tiene un rol explicativo fundamental en la pobreza laboral y que incluso en contextos nacionales distintos

8. A modo de ejemplo, de acuerdo con datos de la Organización Internacional del Trabajo (ILOSTAT), en 2017 solo el $37 \%$ de la fuerza laboral de Bolivia, el $49 \%$ en Colombia y el $45 \%$ en Perú eran asalariados, frente al 84 \% en España y el 88 \% Francia y Finlandia.

9. Los enfoques teóricos sobre el sector informal son diversos y las controversias en torno a su denominación son múltiples. Sin embargo, todas las vertientes teóricas coinciden en registrar la extensión y persistencia de este tipo de actividades laborales como un rasgo característico de los mercados laborales de los países en desarrollo (Cortés, 2000).

10. La perspectiva de problematizar los estratos de productividad ha sido muy utilizada en el caso argentino para examinar el comportamiento del mercado laboral (Poy, 2017; Salvia y Vera, 2013) y, recientemente, para analizar la estructura de las clases sociales en América Latina (Chávez Molina et al., 2019). 
puede identificarse una pauta de estructuración similar de la probabilidad de experimentarla, ligada a clivajes ocupacionales. De esta hipótesis se derivan dos hipótesis particulares.

(a) La estratificación económico-ocupacional será disímil en Argentina y en España, con una mayor incidencia de los rasgos típicos del menor desarrollo económico en el caso del país latinoamericano: se registrará mayor incidencia de las ocupaciones por cuenta propia de baja o nula cualificación, en pequeños establecimientos y mayor precarización de las relaciones laborales.

(b) El tipo de inserción económico-ocupacional retendría fuerte relevancia explicativa sobre la probabilidad de experimentar pobreza laboral, y se reconocería un proceso estructurante similar entre Argentina y España con respecto a las oportunidades relativas de estar en pobreza que enfrentan ciertos grupos de trabajadores.

\section{Fuentes de datos y metodología}

En esta investigación se implementó un diseño comparativo a partir de dos fuentes de datos. Para Argentina, se utilizaron los microdatos de la Encuesta Permanente de Hogares (EPH) del Instituto Nacional de Estadística y Censos (INDEC). La EPH es una encuesta trimestral que releva información en los principales 31 aglomerados urbanos de Argentina. Incluye información sobre la ocupación y los ingresos de todos los integrantes del hogar. La EPH mide los ingresos mensuales de los integrantes de los hogares netos de obligaciones fiscales para el mes anterior al de realización de la encuesta. Se utilizaron los microdatos del cuarto trimestre de 2017. ${ }^{11}$ Para España, se apeló a la Encuesta de Condiciones de Vida (ECV) del Instituto Nacional de Estadística (INE). La ECV fue diseñada para el estudio de la distribución del ingreso y la exclusión social en Europa, es parte de las operaciones estadísticas de la Unión Europea y cubre todas las regiones españolas. Evalúa la renta neta y bruta para los distintos componentes del hogar y otras fuentes de ingreso en el ámbito del hogar durante el año anterior a la realización del relevamiento.

Sobre la base de ambas fuentes se construyó una matriz o tipología de formas de inserción económico-ocupacional de la fuerza de trabajo que recoge los aportes teóricos reseñados previamente. Esta tipología combina la categoría ocupacional, los atributos de las unidades económicas en las que se desempeñan los trabajadores - esencialmente, el tamaño de las empresas- y la "calidad» de su inserción. ${ }^{12}$ Más formalmente, las variables utilizadas en la construcción de este sistema de clasificación fueron:

11. Asimismo, cabe señalar que el tratamiento oficial de la no respuesta de ingresos de la EPH consiste en una sobreexpansión de aquellos casos que declaran ingresos. Aquí se utilizó un método alternativo de imputación de datos faltantes a partir del algoritmo expectation maximization utilizado en investigaciones previas (Vera y Poy, 2017).

12. Esta tipología constituye una adaptación — para favorecer la comparación internacionalde la utilizada en estudios previos (Poy, 2017; Salvia et al., 2018). 
a) La «categoría ocupacional» es utilizada para diferenciar posiciones en las relaciones sociales de producción tal como suele ser habitual en las investigaciones sobre estratificación social.

b) $\mathrm{El}$ "estrato de productividad» permite distinguir entre microempresas, empresas medianas y grandes y establecimientos del sector público para aproximarse a las asimetrías tecnológicas entre empresas y sectores. ${ }^{13} \mathrm{La}$ «cualificación» (profesional o no profesional) brinda una aproximación complementaria, especialmente en el caso de los no asalariados.

c) La "calidad» de las ocupaciones se refiere al tipo y grado de regulación de las relaciones laborales. Distinguimos entre empleos estables o por tiempo indeterminado, empleos con contrato temporal y empleos sin contrato (o extralegales). Con ello se recogen distintas contribuciones sobre la segmentación del mercado de trabajo, especialmente, la distinción entre un segmento "primario» y otro «secundario» anteriormente aludida.

Con respecto a la definición de la pobreza laboral, como se indicó, se adoptó una doble aproximación: se considera a los «trabajadores pobres» y a los «trabajadores en hogares pobres». En ambos casos, se requieren dos decisiones metodológicas: por un lado, la delimitación del universo de trabajadores ocupados y, por otro lado, la definición del umbral o línea de pobreza. Con respecto a la definición de los ocupados, no existe consenso con respecto a su delimitación. El estándar internacional de la OIT define como ocupados a quienes se desempeñaron al menos una hora en una actividad económica durante la semana anterior a la realización de la encuesta. El sistema estadístico argentino (y de muchos países latinoamericanos) sigue este criterio. En los países desarrollados, en cambio, resulta habitual adoptar un criterio temporal más extenso. El sistema estadístico europeo (Eurostat) considera ocupadas a aquellas personas que trabajaron al menos siete meses durante el año anterior al de la realización de la encuesta. Dado que en el caso argentino no fue posible adoptar una definición similar, el universo de trabajadores españoles quedó conformado por los ocupados al momento de realización de la entrevista. A su vez, como en la ECV se relevan los ingresos laborales durante el año anterior al de la entrevista, el análisis se restringió a aquellos trabajadores que tuvieron ingresos durante el período de la renta. ${ }^{14}$

La combinación de los dos enfoques generales para la medición de la pobreza - absoluto y relativo- y las dos aproximaciones ya mencionadas para el tratamiento de la pobreza laboral —individual y del hogar- permitió construir

13. La decisión de tomar el tamaño de establecimiento como aproximación de la productividad se funda en que, en general, existe una importante relación entre costos, escala de producción y productividad. Esta aproximación tiene amplios antecedentes en la literatura (cfr. Gasparini y Tornarolli, 2009) y constituye, en general, la única variable proxy disponible en las encuestas de hogares para caracterizar las unidades económicas.

14. Asimismo, la ECV solo releva datos laborales para la población de 16 años y más, mientras que la EPH lo hace para todos los mayores de 10 años. Por consiguiente, se delimitó el universo de trabajadores a partir del umbral de 16 años y más. 
Figura 1. Matriz económico-ocupacional: tipos de inserción económico-ocupacional de la fuerza de trabajo y su definición operacional

\begin{tabular}{|c|c|}
\hline Inserción económico-ocupacional & Definición operativa \\
\hline Empleadores de empresas medianas y grandes & $\begin{array}{l}\text { Empleadores en establecimientos de más de } 5 \\
\text { ocupados }\end{array}$ \\
\hline Profesionales independientes & $\begin{array}{l}\text { Trabajadores por cuenta propia que no contra- } \\
\text { tan empleados, con calificación profesional }\end{array}$ \\
\hline \multirow[t]{3}{*}{ Empleados del sector público } & $\begin{array}{l}\text { Asalariados en establecimientos del sector } \\
\text { público }\end{array}$ \\
\hline & $\begin{array}{l}\text { Estables: con contrato por tiempo indetermi- } \\
\text { nado }\end{array}$ \\
\hline & Precarios: sin contrato o con contrato temporal \\
\hline \multirow[t]{3}{*}{ Asalariados de empresas medianas y grandes } & $\begin{array}{l}\text { Asalariados en establecimientos de más de } 5 \\
\text { trabajadores }\end{array}$ \\
\hline & $\begin{array}{l}\text { Estables: con contrato por tiempo indetermi- } \\
\text { nado }\end{array}$ \\
\hline & Precarios: sin contrato o con contrato temporal \\
\hline Microempresarios & $\begin{array}{l}\text { Empleadores en establecimientos de hasta } 5 \\
\text { ocupados }\end{array}$ \\
\hline Trabajadores por cuenta propia no profesionales & $\begin{array}{l}\text { Trabajadores por cuenta propia sin calificación } \\
\text { profesional (incluye trabajadores que prestan } \\
\text { servicio doméstico en hogares) }\end{array}$ \\
\hline \multirow[t]{3}{*}{ Asalariados de microempresas } & $\begin{array}{l}\text { Asalariados en establecimientos de hasta } 5 \text { tra- } \\
\text { bajadores en las siguientes condiciones: }\end{array}$ \\
\hline & $\begin{array}{l}\text { Estables: con contrato por tiempo indetermi- } \\
\text { nado }\end{array}$ \\
\hline & Precarios: sin contrato o con contrato temporal \\
\hline
\end{tabular}

Fuente: elaboración propia a partir de EPH (INDEC) y ECV (INE).

Figura 2. Medidas de pobreza laboral comparables en Argentina y España

\begin{tabular}{lll}
\hline Trabajadores pobres & Enfoque absoluto & Ingreso laboral diario inferior a USD 10 PPA(a) \\
\cline { 2 - 3 } & Enfoque relativo & $\begin{array}{l}\text { Ingreso laboral inferior al } 60 \% \text { de la mediana del } \\
\text { ingreso laboral (b) }\end{array}$ \\
\hline $\begin{array}{lll}\text { Trabajadores en } \\
\text { hogares pobres }\end{array}$ & Enfoque absoluto & $\begin{array}{l}\text { Ingreso per cápita familiar (IPCF) diario inferior a USD } \\
10 \mathrm{PPA}^{(\mathrm{a})}\end{array}$ \\
\cline { 2 - 3 } & Enfoque relativo & $\begin{array}{l}\text { Ingreso familiar inferior al } 60 \% \text { de la mediana del } \\
\text { ingreso familiar equivalente(c) }\end{array}$ \\
\hline
\end{tabular}

Notas: (a) constituye el «límite» que separa la situación de pobreza y vulnerabilidad de la «clase media», de acuerdo con un estudio del Banco Mundial (Ferreira et al., 2012) / (b) se sigue el criterio de Filandri y Struffolino (2019) / (c) el ingreso familiar equivalente es el total de ingresos dividido por unidad de consumo según una escala de equivalencias conocida como «escala OCDE modificada» y utilizada actualmente tanto por Eurostat como por la OCDE.

Fuente: elaboración propia. 
cuatro medidas (figura 2). Desde un enfoque absoluto, se definió como trabajadores en hogares pobres a aquellos cuyo ingreso per cápita familiar diario en dólares a paridad del poder adquisitivo (PPA) es inferior a USD 10 PPA. Este umbral se adecua a las características y al nivel de desarrollo de los países bajo estudio y ha sido utilizado en investigaciones del Banco Mundial para establecer el límite a partir del cual se supera la pobreza y la vulnerabilidad (Ferreira et al., 2012). ${ }^{15}$ Siguiendo esta lógica, se definió como trabajadores pobres a aquellos ocupados cuyo ingreso diario es inferior a dicho umbral. Por su parte, desde un enfoque relativo, se definió como trabajadores en hogares pobres a aquellos ocupados cuyo ingreso familiar por unidad de consumo equivalente (según la escala de equivalencias de la Organización para la Cooperación y el Desarrollo Económico, OCDE) es inferior al $60 \%$ de la mediana del ingreso por unidad equivalente en la distribución del total de personas. Desde el mismo enfoque, se definió como trabajadores pobres a aquellos ocupados con ingresos laborales inferiores al $60 \%$ de la mediana del ingreso laboral total (Filandri y Struffolino, 2019).

Para modelar la probabilidad de experimentar pobreza laboral, se apela a un análisis de regresión logística binaria. Se trata de un procedimiento adecuado cuando la variable dependiente es dicotómica y se quiere evaluar el impacto que tienen diferentes variables independientes en la ocurrencia de un evento. En términos formales, la probabilidad de que un trabajador se encuentre en situación de pobreza laboral se expresa como:

$$
\operatorname{Pr}(\mathrm{y}=1 \mid \mathrm{x})=\frac{1}{1+\mathrm{e}^{-\mathrm{z}}}(1)
$$

En un modelo de regresión logística binaria múltiple, $z$ asume la siguiente forma:

$$
\mathrm{z}=a+b_{1} x_{1}+\ldots+b_{\mathrm{n}} x_{\mathrm{n}}(2)
$$

En este modelo, la principal variable independiente es la posición del trabajador en la estructura económico-ocupacional. Sin embargo, se introducen otras covariables que nos permiten controlar la relación propuesta y, a la vez, aportar información relevante sobre factores que inciden en la pobreza laboral. Estas variables remiten a dimensiones que la literatura reconoce como determinantes y que se refieren, principalmente, a características individuales (sexo, edad, nivel educativo y nacionalidad) y del hogar (tipo de hogar, cantidad de niños, número de perceptores laborales) (figura 3). Se estimaron dos modelos de regresión para cada país considerando las dos definiciones distintas de la variable dependiente: trabajadores pobres y trabajadores que viven en hogares pobres. En todos los casos se apeló a la medición relativa dado que la baja

15. Dentro del enfoque absoluto, son conocidas las líneas de pobreza extrema y moderadas que sugiere el Banco Mundial para la comparabilidad internacional (USD 1,90, USD 3,20 y USD 5,50 PPA). Sin embargo, se descartó su utilización dada la casi inexistente incidencia de la pobreza en los países estudiados según estos umbrales. 
Figura 3. Variables independientes adicionales introducidas en los modelos de regresión logística.

\begin{tabular}{|c|c|c|}
\hline Variable & Descripción & Categorías \\
\hline \multirow[t]{2}{*}{ Sexo } & \multirow[t]{2}{*}{ Género del encuestado/a } & Mujer \\
\hline & & Varón \\
\hline \multirow[t]{3}{*}{ Edad } & \multirow[t]{3}{*}{ Edad del encuestado/a } & 30 a 44 años \\
\hline & & 16 a 29 años \\
\hline & & 45 años y más \\
\hline \multirow[t]{3}{*}{ Educación } & \multirow{3}{*}{$\begin{array}{l}\text { Máximo nivel de estudios } \\
\text { completado por el } \\
\text { encuestado/a }\end{array}$} & Hasta secundaria incompleta \\
\hline & & $\begin{array}{l}\text { Secundaria completa o superior/universi- } \\
\text { tario incompleto }\end{array}$ \\
\hline & & Superior/universitario completo \\
\hline \multirow[t]{2}{*}{ Nacionalidad } & \multirow{2}{*}{$\begin{array}{l}\text { Origen migratorio del } \\
\text { encuestado/a }\end{array}$} & Nativo (argentino/español) \\
\hline & & Extranjero \\
\hline \multirow{3}{*}{$\begin{array}{l}\text { Presencia de menores } \\
\text { de } 18 \text { años en el hogar }\end{array}$} & \multirow{3}{*}{$\begin{array}{l}\text { Cantidad de menores de } \\
18 \text { años en el hogar del } \\
\text { encuestado/a }\end{array}$} & Sin niños/as \\
\hline & & Un niño/a \\
\hline & & Dos o más niños/as \\
\hline \multirow[t]{3}{*}{ Tipo de hogar } & \multirow{3}{*}{$\begin{array}{l}\text { Describe la configuración } \\
\text { familiar según el tipo de } \\
\text { núcleo conyugal en el } \\
\text { hogar del encuestado/a }\end{array}$} & Unipersonal \\
\hline & & $\begin{array}{l}\text { Conyugal completo (ambos cónyuges } \\
\text { presentes en hogar multipersonal) }\end{array}$ \\
\hline & & $\begin{array}{l}\text { Conyugal incompleto (solo un cónyuge } \\
\text { presente en hogar multipersonal) }\end{array}$ \\
\hline \multirow{2}{*}{$\begin{array}{l}\text { Cantidad de ocupados } \\
\text { en el hogar }\end{array}$} & \multirow{2}{*}{$\begin{array}{l}\text { Cantidad de miembros } \\
\text { ocupados en el hogar del } \\
\text { encuestado/a }\end{array}$} & Un ocupado/a \\
\hline & & Dos o más ocupados/as \\
\hline Rama de actividad & $\begin{array}{l}\text { Rama de actividad } \\
\text { en la que se ocupa el } \\
\text { encuestado/a, según la } \\
\text { Clasificación Nacional de } \\
\text { Actividades Económicas } \\
\text { (España) y el Clasificador } \\
\text { de Actividades Económicas } \\
\text { CAES Mercosur (Argentina) }\end{array}$ & $\begin{array}{l}\text { Industria, construcción, comercio y hos- } \\
\text { telería, transporte-comunicaciones, acts. } \\
\text { financieras y profesionales, administra- } \\
\text { ción pública, otros servicios } \\
\end{array}$ \\
\hline \multirow[t]{2}{*}{ Región } & \multirow[t]{2}{*}{$\begin{array}{l}\text { Región de residencia del } \\
\text { encuestado/a }\end{array}$} & $\begin{array}{l}\text { Argentina: Gran Buenos Aires, Noreste, } \\
\text { Noroeste, región Pampeana, Cuyo y } \\
\text { región Patagónica }\end{array}$ \\
\hline & & $\begin{array}{l}\text { España: 1- Andalucía, Murcia, Ceuta, } \\
\text { Melilla, Canarias y Extraregión; 2- País } \\
\text { Vasco, Navarra, La Rioja, Aragón; } \\
3 \text {-Madrid, Castilla-La Mancha, Castilla } \\
\text { y León, Extremadura; } 4 \text { - Cataluña, } \\
\text { Valencia, Islas Baleares; 5- Galicia, } \\
\text { Asturias, Cantabria }\end{array}$ \\
\hline
\end{tabular}

Fuente: elaboración propia a partir de EPH (INDEC) y ECV (INE). 
incidencia de la pobreza absoluta en el caso español dificultaba un análisis multivariante.

\section{Resultados}

Los resultados se presentan en dos apartados. En el primero se analizan las características de la estratificación económico-ocupacional en Argentina y en España en función de la tipología presentada. En el segundo apartado se examinan la incidencia y los determinantes de la pobreza laboral a partir de un análisis descriptivo y de la aplicación de dos modelos multivariantes de regresión logística.

\subsection{Estratificación económico-ocupacional en perspectiva comparada}

Según la primera hipótesis específica, cabría esperar que la estratificación del mercado de trabajo sea disímil en Argentina y en España, principalmente por sus diferentes niveles de desarrollo económico. En este sentido, debería observarse una acentuación de aquellos rasgos socioocupacionales más típicos del menor nivel de desarrollo en el país latinoamericano: mayor incidencia de las ocupaciones por cuenta propia de baja o nula cualificación, en pequeños establecimientos y en hogares y una mayor precarización de las relaciones laborales.

La tabla 1 presenta la distribución de la fuerza de trabajo según la posición económico-ocupacional en ambos países. Puede advertirse que el perfil de estratificación económico-ocupacional diverge principalmente con respecto a la significación que adquiere en cada país el sector de microempresas, el trabajo independiente de baja cualificación y en hogares. Como se señaló, la literatura suele identificar estas posiciones laborales con el "sector informal», que se caracteriza por su baja productividad y constituye un rasgo característico de las economías periféricas (Gasparini y Tornarolli, 2009; Salvia et al., 2018). En Argentina, el 43,7 \% de la fuerza de trabajo se desempeña en este tipo de actividades, mientras que en España solo lo hace el 24,2 \% de los trabajadores. De manera más desagregada, el cuentapropismo no profesional triplica su incidencia relativa en Argentina en comparación con España (el 26,3 \% frente al 9,4\%) y también se incrementa el empleo asalariado en microunidades (el $15,1 \%$ frente al 11,7 \%). Estos rasgos del perfil de estratificación económicoocupacional son compensados en el país europeo con una mayor incidencia del empleo asalariado en empresas grandes y medianas: el 50,7 \% de los trabajadores españoles se desempeñan en este tipo de unidades productivas, frente al 34,5\% de sus pares argentinos. En cambio, no hay diferencias sustantivas en lo que se refiere a la incidencia de los empleadores, los profesionales independientes y los empleados del sector público.

La tabla 1 exhibe diferencias en la estructuración del mercado laboral y también da cuenta de algunas particularidades con respecto al empleo asalariado precario o desprotegido. La literatura coincide en señalar el carácter extendido de la precariedad laboral para ambos países. Banyuls y Recio (2017a: 
Tabla 1. Distribución de la población ocupada según posición económico-ocupacional. Población ocupada de 16 años y más. Argentina y España, año 2017 (en porcentaje)

\begin{tabular}{lrr}
\hline & Argentina & España \\
\hline Empleadores de empresas medianas y grandes & 1,4 & 1,5 \\
Profesionales independientes & 2,1 & 2,8 \\
Empleados del sector público & 18,3 & 20,8 \\
$\quad$ Estables/protegidos & 15,5 & 17,1 \\
$\quad$ Precarios & 2,8 & 3,6 \\
Asalariados de empresas medianas y grandes & 34,5 & 50,7 \\
$\quad$ Estables/protegidos & 26,6 & 38,6 \\
$\quad$ Precarios & 7,9 & 12,1 \\
Microempresarios & 2,3 & 3,1 \\
Trabajadores por cuenta propia no profesionales & 26,3 & 9,4 \\
Asalariados de microempresas & 15,1 & 11,7 \\
$\quad$ Estables/protegidos & 4,0 & 8,2 \\
$\quad$ Precarios & 11,1 & 3,5 \\
Total & 100,0 & 100,0 \\
\hline Empresas medianas y grandes, trabajo independiente profesional & 56,3 & 75,8 \\
$\quad$ y sector público (\%) & & \\
Ocupados en microempresas, trabajo independiente no profesional & 43,7 & 24,2 \\
$\quad$ y en hogares (\%) & & \\
Trabajadores precarios (\% asalariados) & 32,2 & 23,1 \\
Observaciones & 24.349 & 9.358 \\
\hline
\end{tabular}

Fuente: elaboración propia a partir de microdatos de EPH (INDEC) y ECV (INE).

143) indican que en España se explica por los cambios normativos que facilitan la temporalidad y por la difusión de las empresas de tercerización. En Argentina, el modelo de fuerte regulación coexiste con el abierto incumplimiento de la normativa laboral (Poy, 2017). En ambos países, la precarización laboral se vería acentuada por la elevada incidencia de las microempresas como demandantes de fuerza de trabajo. Si se consideran el total de trabajadores asalariados, el análisis comparativo permite advertir que Argentina tiene mayor incidencia de trabajadores precarios que España (el 32,2 \% frente al 23,1\%).

Dado el propósito del artículo de examinar la relación entre los procesos de estratificación del mercado de trabajo y la pobreza laboral, la tabla 2 exhibe estadísticos del ingreso total laboral para las diferentes categorías ocupacionales. El disímil grado de desarrollo económico entre ambos países se traduce en los niveles de ingresos medidos a igualdad de poder de compra: los trabajadores españoles tienen ingresos un $66 \%$ superiores a los de los argentinos (USD 2.234 frente a USD 1.348, PPA).

A su vez, la tabla 2 también revela que, más allá de estas diferencias de niveles, la inserción económico-ocupacional correlaciona estrechamente con las remuneraciones laborales en ambos países, y el examen de las brechas brutas revela que la pauta de inequidad es muy similar. Los trabajadores por cuenta 
Tabla 2. Estadísticas descriptivas del ingreso laboral mensual. Población ocupada de 16 años y más. Argentina y España, año 2017 (en dólares PPA)

\begin{tabular}{|c|c|c|c|c|c|c|}
\hline & \multicolumn{3}{|c|}{ Argentina } & \multicolumn{3}{|c|}{ España } \\
\hline & Media & $\begin{array}{l}\text { Desv. } \\
\text { estándar }\end{array}$ & $\begin{array}{c}\text { Brecha } \\
\text { bruta }\end{array}$ & Media & $\begin{array}{l}\text { Desv. } \\
\text { estándar }\end{array}$ & $\begin{array}{c}\text { Brecha } \\
\text { bruta }\end{array}$ \\
\hline $\begin{array}{l}\text { Empleadores de empresas medianas } \\
\text { y grandes }\end{array}$ & 2.868 & 2.430 & 2,1 & 4.130 & 4.003 & 1,8 \\
\hline Profesionales independientes & 2.107 & 1.709 & 1,6 & 2.204 & 2.108 & 1,0 \\
\hline Empleados del sector público & 1.732 & 1.080 & 1,3 & 3.042 & 1.521 & 1,4 \\
\hline Estables/protegidos & 1.855 & 1.073 & 1,4 & 3.126 & 1.499 & 1,4 \\
\hline Precarios & 1.025 & 820 & 0,8 & 2.033 & 1,280 & 0,9 \\
\hline $\begin{array}{l}\text { Asalariados de empresas medianas } \\
\text { y grandes }\end{array}$ & 1.564 & 909 & 1,2 & 2.333 & 1.544 & 1,0 \\
\hline Estables/protegidos & 1.700 & 871 & 1,3 & 2.506 & 1.605 & 1,1 \\
\hline Precarios & 1.087 & 881 & 0,8 & 1.423 & 967 & 0,6 \\
\hline Microempresarios y cuentapropistas & 904 & 855 & 0,7 & 1.574 & 1.480 & 0,7 \\
\hline Asalariados de microempresas & 965 & 600 & 0,7 & 1.682 & 1.228 & 0,8 \\
\hline Estables/protegidos & 1.363 & 643 & 1,0 & 1.859 & 1.209 & 0,8 \\
\hline Precarios & 830 & 520 & 0,6 & 1.213 & 1.153 & 0,5 \\
\hline Total & 1.348 & 1.035 & 1,0 & 2.234 & 1.664 & 1,0 \\
\hline $\begin{array}{l}\text { Empresas medianas y grandes, trabajo } \\
\text { independiente profesional y sector } \\
\text { público (I) }\end{array}$ & 1.670 & 1.088 & 1,2 & 2.468 & 1.698 & 1,1 \\
\hline $\begin{array}{l}\text { Microempresas, trabajo independiente } \\
\text { no profesional y en hogares (II) }\end{array}$ & 924 & 779 & 0,7 & 1.589 & 1.370 & 0,7 \\
\hline
\end{tabular}

Estadísticos: Argentina: Eta cuadrado = 0,197 F = 749,86 (0,000) / España: Eta cuadrado = 0,152 F=297,34 (0,000). Fuente: elaboración propia a partir de microdatos de EPH (INDEC) y ECV (INE).

propia de baja cualificación, los microempresarios y los asalariados de microempresas son los ocupados peor posicionados en ambos países. A su vez, tanto en Argentina como en España se observa que los trabajadores de microempresas ganan menos que los asalariados de establecimientos medianos y grandes o del sector público, y a dicha penalidad se le añade la desventaja asociada a precariedad. Solo se advierte una diferencia sustantiva entre los profesionales independientes españoles, pues están significativamente desaventajados en términos comparativos con otros grupos de la estructura económico-ocupacional española si se compara con la posición relativa de sus pares argentinos. ${ }^{16}$

En suma, en la dirección propuesta por la primera hipótesis particular, existen diferencias estructurales relevantes entre Argentina y España que se expresan en el perfil de estratificación laboral y en el nivel de ingresos. La

16. Estos resultados son coherentes con los reportados por Semenza y Sarti (2018), quienes indican que los profesionales independientes italianos son más desfavorecidos que los argentinos porque la prima de ingresos a la educación se reduce en el país europeo. 
estructura ocupacional argentina se caracteriza por una mayor incidencia del empleo en microunidades, de trabajo independiente de baja cualificación o en hogares. Ambas estructuras ocupacionales tienen una elevada incidencia de la precariedad laboral, pero se encuentra más extendida en el país latinoamericano. Más allá de estas diferencias, se advierte que el perfil de estratificación se asocia con una pauta de desigualdad de ingresos laborales parecida: a pesar de tener una incidencia disímil, las distintas categorías económico-ocupacionales se encuentran jerarquizadas de manera semejante. Estos resultados contribuirían a aquellas investigaciones que plantean una organización similar de las desigualdades laborales en Argentina y España (López-Roldán y Fachelli, 2019).

\subsection{Trabajadores pobres y trabajadores en hogares pobres}

La segunda hipótesis particular de este artículo sugiere que el tipo de inserción económico-ocupacional de los trabajadores cumple un papel explicativo clave en la probabilidad de experimentar pobreza laboral, y que puede reconocerse un proceso estructurante similar con respecto a las oportunidades relativas de estar en pobreza que enfrentan ciertos grupos de trabajadores. Según esta hipótesis, cabría esperar que en ambos países las variables de estratificación del mercado laboral desempeñen un papel clave en la determinación de la probabilidad de experimentar pobreza laboral de tal modo que ciertos grupos concentren la mayor propensión.

Como primera aproximación descriptiva al análisis comparativo de la pobreza laboral, el gráfico 1 exhibe los niveles de incidencia según las distintas

Gráfico 1. Incidencia de la pobreza laboral en Argentina y España. Población ocupada de 16 años y más. Argentina y España, año 2017 (en porcentajes)

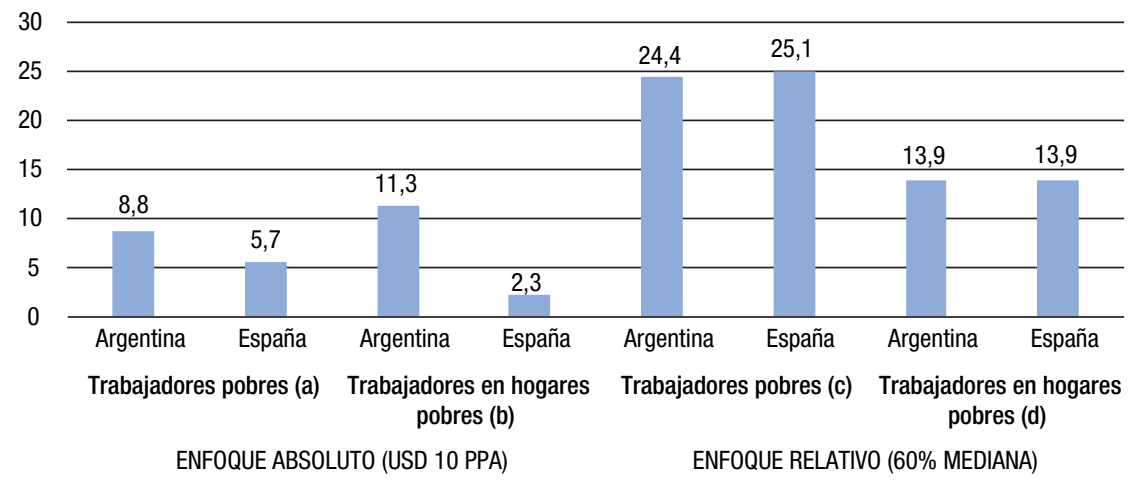

Notas: (a) trabajadores con ingresos laborales diarios inferiores a USD 10 PPA / (b) trabajadores en hogares cuyo ingreso per cápita familiar (IPCF) diario es inferior a USD 10 PPA / (c) trabajadores con ingresos laborales inferiores al $60 \%$ de la mediana del ingreso laboral / (d) trabajadores en hogares con ingresos inferiores al $60 \%$ de la mediana del ingreso familiar equivalente (según la escala OCDE).

Fuente: elaboración propia a partir de microdatos de EPH (INDEC) y ECV (INE). 
Gráfico 2. Distribución de los trabajadores pobres y de los trabajadores en hogares pobres según categoría económico-ocupacional. Argentina y España, año 2017 (en porcentajes)

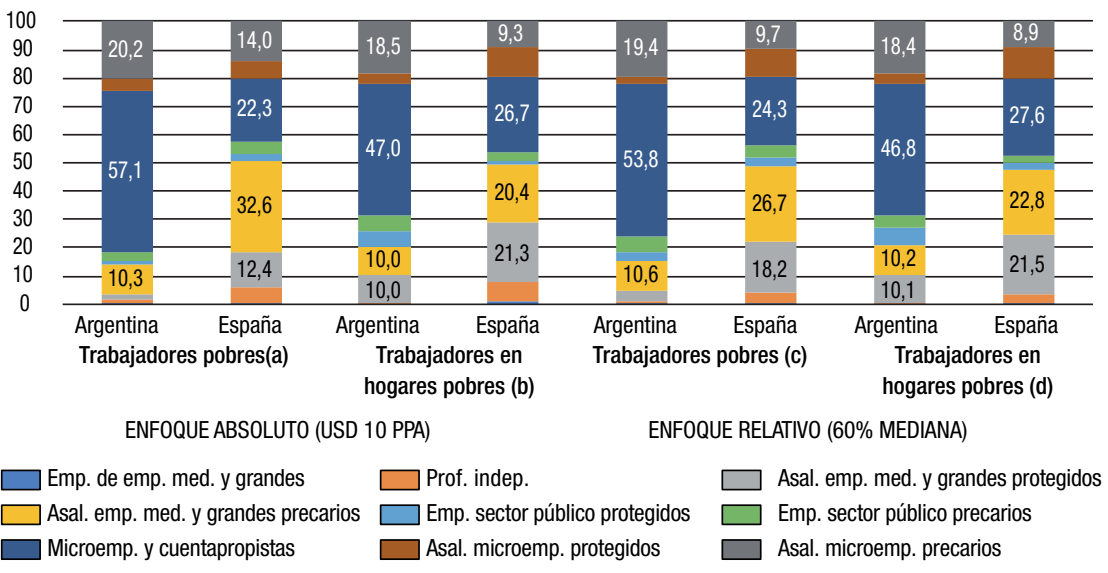

Notas: (a) trabajadores con ingresos laborales diarios inferiores a USD 10 PPA / (b) trabajadores en hogares cuyo ingreso per cápita familiar (IPCF) diario es inferior a USD 10 PPA / (c) trabajadores con ingresos laborales inferiores al $60 \%$ de la mediana del ingreso laboral / (d) trabajadores en hogares con ingresos inferiores al $60 \%$ de la mediana del ingreso familiar equivalente (según la escala OCDE).

Fuente: elaboración propia a partir de microdatos de EPH (INDEC) y ECV (INE).

medidas construidas. En primer lugar, las medidas que remiten a un enfoque absoluto - ya sea desde la perspectiva individual o del hogar- exhiben los desiguales niveles de desarrollo entre Argentina y España: mientras que en el país latinoamericano el 8,8 \% de los trabajadores son pobres y el $11,3 \%$ viven en hogares pobres, estas cifras son del 5,7 \% y el 2,3\% en el país europeo. El hecho de que la pobreza absoluta se incremente al considerar la perspectiva del hogar en Argentina y que se reduzca en España indica que el efecto de pooling de ingresos (Peña-Casas y Ghailani, 2011) es disímil en cada país. En segundo lugar, las medidas relativas son congruentes con los datos descriptivos de ingresos ya revisados: tanto desde la perspectiva individual como desde el enfoque del hogar, la incidencia de la pobreza laboral es similar en Argentina y en España. Una cuarta parte de los trabajadores ocupados en ambos países son pobres porque tienen ingresos inferiores al $60 \%$ de la mediana de los ingresos laborales y un 13,9\% vive en hogares pobres. ${ }^{17}$

Detrás de estas semejanzas se advierte una muy disímil composición del universo de trabajadores pobres y de trabajadores en hogares pobres (gráfico 2). En Argentina, alrededor de tres cuartas partes de dicho universo se componen de microempresarios, trabajadores por cuenta propia de baja cualificación y asalariados precarios de microunidades. En España, en cambio, la pobreza laboral remite a un universo más heterogéneo, con un alto predominio de trabajadores

17. Los ejercicios realizados con otros umbrales (50\% y $40 \%$ de la mediana) y con los ingresos laborales horarios arrojaron resultados semejantes a los reportados aquí. 
Tabla 3. Regresión logística de la pobreza laboral (ingreso laboral por debajo del $60 \%$ de la mediana) en Argentina y España

\begin{tabular}{|c|c|c|c|c|c|c|}
\hline & \multicolumn{3}{|c|}{ Argentina } & \multicolumn{3}{|c|}{ España } \\
\hline & B & Odds ratio & PEM & B & Odds ratio & PEM \\
\hline \multicolumn{7}{|l|}{ Sexo } \\
\hline \multicolumn{7}{|l|}{ Varón @ } \\
\hline Mujer & $1,054^{\star \star \star}$ & $2,868^{\star \star \star}$ & $0,130^{\star \star \star}$ & $0,632^{\star \star \star}$ & $1,882^{\star \star \star}$ & $0,086^{\star \star \star}$ \\
\hline \multicolumn{7}{|l|}{ Edad } \\
\hline \multicolumn{7}{|l|}{30 a 44 años $\odot$} \\
\hline 16 a 29 años & $0,719^{\star \star \star}$ & $2,053^{\star \star \star}$ & $0,092^{\star \star \star}$ & $0,846^{\star \star \star}$ & $2,329^{\star \star \star}$ & $0,131^{\star \star \star}$ \\
\hline 45 años y más & 0,096 & 1,101 & 0,011 & $-0,182^{\star \star}$ & $0,834^{\star *}$ & $-0,025^{\star \star}$ \\
\hline \multicolumn{7}{|l|}{ Educación } \\
\hline \multicolumn{7}{|l|}{ Univ. Comp. ○) } \\
\hline Hasta Sec. Inc. & $1,634^{\star \star \star}$ & $5,125^{\star \star \star}$ & $0,195^{\star \star \star}$ & $0,912^{\star \star \star}$ & $2,490^{\star \star \star}$ & $0,128^{\star \star \star}$ \\
\hline Sec. Comp. & $0,978^{\star \star \star}$ & $2,659^{\star \star \star}$ & $0,105^{\star \star \star}$ & $0,680^{\star \star \star}$ & $1,974^{\star \star \star}$ & $0,092^{\star \star \star}$ \\
\hline \multicolumn{7}{|l|}{ Nacionalidad } \\
\hline \multicolumn{7}{|l|}{ Nativo @ } \\
\hline Extranjero & $-0,376^{\star \star \star}$ & $0,687^{\star \star \star}$ & $-0,046^{\star \star \star}$ & $0,283^{*}$ & $1,328^{\star}$ & $0,039^{\star}$ \\
\hline \multicolumn{7}{|l|}{ Niños en el hogar } \\
\hline \multicolumn{7}{|l|}{ Sin niños $\odot$} \\
\hline Un niño & 0,021 & 1,021 & 0,003 & $-0,156$ & 0,856 & $-0,021$ \\
\hline Dos o más niños & 0,033 & 1,033 & 0,004 & $-0,206^{*}$ & $0,814^{*}$ & $-0,028^{*}$ \\
\hline \multicolumn{7}{|l|}{ Categoría económico-ocupacional } \\
\hline \multicolumn{7}{|l|}{ Emp. de emp. med. y grandes ( $)$} \\
\hline Prof. indep. & $1,145^{\star \star}$ & $3,144^{\star \star}$ & $0,104^{\star \star *}$ & $1,537^{\star \star \star}$ & $4,650^{\star \star *}$ & $0,247^{\star \star \star}$ \\
\hline Emp. sector público proteg. & $-0,140$ & 0,870 & $-0,008$ & $-0,884^{\star *}$ & $0,413^{\star \star}$ & $-0,069^{*}$ \\
\hline Emp. sector público precarios & $2,472^{\star \star \star}$ & $11,850^{\star \star \star}$ & $0,322^{\star \star \star}$ & $1,071^{\star \star \star}$ & $2,918^{\star \star \star}$ & $0,155^{\star \star \star}$ \\
\hline Asal. emp. med. y grandes proteg. & $-0,307$ & 0,736 & $-0,017$ & 0,085 & 1,088 & 0,009 \\
\hline Asal. emp. med. y grandes precarios & $2,090^{\star \star \star}$ & $8,085^{\star \star \star}$ & $0,249^{\star \star \star}$ & $1,994^{\star \star \star}$ & $7,348^{\star \star \star}$ & $0,346^{\star \star \star}$ \\
\hline Microemp. y cuentapropistas & $2,391^{\star \star \star}$ & $10,920^{\star \star \star}$ & $0,306^{\star \star \star}$ & $1,768^{\star \star \star}$ & $5,860^{\star \star \star}$ & $0,296^{\star \star \star}$ \\
\hline Asal. microemp. proteg. & $1,237^{\star \star \star}$ & $3,445^{\star \star \star}$ & $0,116^{\star \star \star}$ & $0,902^{\star \star \star}$ & $2,465^{\star \star \star}$ & $0,125^{\star \star \star}$ \\
\hline Asal. microemp. precarios & $2,447^{\star \star \star}$ & $11,550^{\star \star \star}$ & $0,317^{\star \star \star}$ & $2,506^{\star \star \star}$ & $12,250^{\star \star \star}$ & $0,459^{\star \star \star}$ \\
\hline Dummies de rama & & Sí & & & Sí & \\
\hline Dummies de región & & Sí & & & Sí & \\
\hline Constante & $-5,415^{\star \star \star}$ & $0,004^{\star \star \star}$ & & $-3,053^{\star \star \star}$ & $0,047^{\star \star \star}$ & \\
\hline \multicolumn{7}{|l|}{ Estadísticos del modelo } \\
\hline Observaciones & 24.349 & & & 9.358 & & \\
\hline R2 de McFadden & 0,309 & & & 0,247 & & \\
\hline$\%$ global de aciertos & $78,69 \%$ & & & $77,59 \%$ & & \\
\hline
\end{tabular}

Notas: () categoría de comparación / significancia de los efectos: ${ }^{* \star \star} p<0,01,{ }^{\star \star} p<0,05,{ }^{*} p<0,1$.

Fuente: elaboración propia a partir de microdatos de EPH (INDEC) y ECV (INE). 
asalariados precarios (de empresas medianas y grandes y, en menor grado, de microempresas) e incluso de trabajadores protegidos. Esta disímil composición del universo de trabajadores pobres traduce las diferencias en los perfiles de estratificación y plantea distintas exigencias de política pública.

A continuación, se discuten los resultados de la aplicación de modelos multivariantes de regresión logística. El primer modelo (tabla 3) examina los determinantes de la probabilidad de que un trabajador tenga un ingreso laboral inferior al $60 \%$ de la mediana. ${ }^{18} \mathrm{Si}$ se toman en cuenta las covariables introducidas, se advierte que tanto en Argentina como en España las mujeres tienen más probabilidad que los varones de ser trabajadoras pobres (13 pp. y 8,6 pp., respectivamente), y que los jóvenes se encuentran más expuestos que los adultos, en particular en España (9,2 pp. frente a 13,1 pp.). Estos resultados coinciden con las evidencias disponibles para Argentina y España sobre la mayor vulnerabilidad de estos grupos sociales (Poy, 2017; Verd y LópezAndreu, 2016). Por su parte, los trabajadores de menor nivel educativo son más proclives a la pobreza, y ello es así con mayor intensidad en Argentina que en España. En contraste, el origen migratorio del trabajador desempeña un papel disímil: en España se asocia con una mayor exposición a la pobreza laboral, y en Argentina, con una protección. Este resultado podría deberse a un perfil disímil de los migrantes en cada país o a comportamientos laborales diferenciados. Por su parte, la presencia de niños en el hogar no desempeña un papel estadísticamente relevante en ninguno de los países estudiados.

Si se consideran los coeficientes estimados, la inserción en la estructura económico-ocupacional constituye el factor con mayor peso explicativo sobre la probabilidad de experimentar pobreza laboral en ambos países. Los asalariados protegidos de empresas medianas y grandes y los empleados del sector público tienen similares probabilidades de estar en pobreza que los empleadores de empresas grandes y medianas (por ello, los coeficientes asociados no son estadísticamente significativos). ${ }^{19}$ En ambos países se advierte con claridad que los trabajadores más desaventajados son los asalariados precarios, los microempresarios y los cuentapropistas de baja cualificación.

En todos los casos, los efectos atribuibles al tamaño del establecimiento y a la precariedad interactúan. Los asalariados precarios tienen más chances de ser pobres que sus pares no precarios, y este efecto se intensifica entre los que se desempeñan en microestablecimientos en comparación con los asalariados de empresas medianas y grandes. Estos resultados evidencian la importancia de considerar la categoría ocupacional y la cualificación en

18. En los modelos de regresión logística es habitual reportar las razones de momios (odds ratios). Como existe discusión acerca de la comparabilidad de los odds ratios obtenidos a partir de muestras distintas (Mood, 2010), se presentan y analizan los "promedios de efectos marginales» (average marginal effects) —PEM- Para una discusión detallada de este tema, véase Ballesteros (2018).

19. Como se apreció en el apartado anterior, aquí también se advierte que los profesionales independientes están más expuestos al riesgo de experimentar pobreza laboral en España que en Argentina. 
Tabla 4. Regresión logística de la pobreza laboral (trabajadores en hogares con ingreso familiar por debajo del $60 \%$ de la mediana) en Argentina y España

\begin{tabular}{|c|c|c|c|c|c|c|}
\hline & \multicolumn{3}{|c|}{ Argentina } & \multicolumn{3}{|c|}{ España } \\
\hline & B & Odds ratio & PEM & B & Odds ratio & PEM \\
\hline \multicolumn{7}{|l|}{ Sexo } \\
\hline \multicolumn{7}{|l|}{ Varón @ } \\
\hline Mujer & 0,140 & 1,150 & 0,012 & 0,012 & 1,012 & 0,001 \\
\hline \multicolumn{7}{|l|}{ Edad } \\
\hline \multicolumn{7}{|l|}{30 a 44 años $@$} \\
\hline 16 a 29 años & $0,381^{\star \star \star}$ & $1,464^{\star \star \star}$ & $0,036^{\star \star \star}$ & $0,721^{\star \star \star}$ & $2,056^{\star \star \star}$ & $0,075^{\star \star \star}$ \\
\hline 45 años y más & $-0,028$ & 0,972 & 0,002 & 0,153 & 1,165 & 0,014 \\
\hline \multicolumn{7}{|l|}{ Educación } \\
\hline \multicolumn{7}{|l|}{ Univ. Comp. @ } \\
\hline Hasta Sec. Inc. & $2,065^{\star \star \star}$ & $7,889^{\star \star \star}$ & $0,155^{\star \star \star}$ & $0,839^{\star \star \star}$ & $2,313^{\star \star \star}$ & $0,079^{\star \star \star}$ \\
\hline Sec. Comp. & $1,232^{\star \star \star}$ & $3,427^{\star \star \star}$ & $0,070^{\star \star \star}$ & $0,626^{\star \star \star}$ & $1,869^{\star \star \star}$ & $0,056^{\star \star \star}$ \\
\hline \multicolumn{7}{|l|}{ Nacionalidad } \\
\hline \multicolumn{7}{|l|}{ Nativo @) } \\
\hline Extranjero & 0,216 & 1,241 & 0,019 & $1,032^{\star \star \star}$ & $2,806^{\star \star \star}$ & $0,097^{\star \star \star}$ \\
\hline \multicolumn{7}{|l|}{ Tipo de hogar } \\
\hline \multicolumn{7}{|l|}{ Conyugal completo $\odot$} \\
\hline Unipersonal & $-0,618^{\star \star \star}$ & $0,539^{\star \star \star}$ & $-0,049^{\star \star \star}$ & 0,241 & 1,273 & 0,024 \\
\hline Conyugal incompleto & 0,064 & 1,066 & 0,006 & $0,743^{\star \star \star}$ & $2,103^{\star \star \star}$ & $0,081^{\star \star \star}$ \\
\hline \multicolumn{7}{|l|}{ Niños en el hogar } \\
\hline \multicolumn{7}{|l|}{ Sin niños @ } \\
\hline Un niño & $0,898^{\star \star *}$ & $2,454^{\star \star \star}$ & $0,067^{\star \star \star}$ & $0,556^{\star \star \star}$ & $1,744^{\star \star \star}$ & $0,051^{\star \star \star}$ \\
\hline Dos o más niños & $1,736^{\star \star \star}$ & $5,675^{\star \star \star}$ & $0,163^{\star \star \star}$ & $1,106^{\star \star \star}$ & $3,021^{\star * *}$ & $0,116^{\star \star \star}$ \\
\hline \multicolumn{7}{|l|}{ Ocupados en el hogar } \\
\hline \multicolumn{7}{|l|}{ Un ocupado $\odot$} \\
\hline Dos o más ocupados & $-1,618^{\star \star \star}$ & $0,198^{\star \star \star}$ & $-0,144^{\star \star \star}$ & $-0,957^{\star \star \star}$ & $0,384^{\star \star \star}$ & $-0,090^{\star \star \star}$ \\
\hline \multicolumn{7}{|l|}{ Categoría económico-ocupacional } \\
\hline \multicolumn{7}{|l|}{ Emp. de emp. med. y grandes @ } \\
\hline Prof. indep. & $1,509^{\star \star}$ & $4,523^{\star \star}$ & $0,072^{\star \star}$ & $1,171^{\star \star}$ & $3,227^{\star \star}$ & $0,106^{\star \star}$ \\
\hline Emp. sector público proteg. & $1,180^{\star \star}$ & $3,255^{\star \star}$ & $0,050^{\star \star \star}$ & $-0,923$ & 0,397 & $-0,040$ \\
\hline Emp. sector público precarios & $2,458^{\star \star \star}$ & $11,690^{\star \star \star}$ & $0,163^{\star \star \star}$ & 0,495 & 1,641 & 0,036 \\
\hline Asal. emp. med. y grandes proteg. & $0,927^{*}$ & $2,526^{\star}$ & $0,035^{\star \star}$ & 0,261 & 1,298 & 0,017 \\
\hline Asal. emp. med. y grandes precarios & $2,176^{\star \star \star}$ & $8,813^{\star \star \star}$ & $0,132^{\star \star \star}$ & $1,456^{\star \star \star}$ & $4,288^{\star \star \star}$ & $0,144^{\star \star *}$ \\
\hline Microemp. y cuentapropistas & $2,369^{\star \star \star}$ & $10,690^{\star \star \star}$ & $0,153^{\star \star \star}$ & $1,566^{\star \star \star}$ & $4,789^{\star \star \star}$ & $0,161^{\star \star *}$ \\
\hline Asal. microemp. proteg. & $1,950^{\star \star \star}$ & $7,030^{\star \star *}$ & $0,109^{\star \star \star}$ & $1,098^{\star \star}$ & $2,997^{\star \star}$ & $0,097^{\star \star \star}$ \\
\hline Asal. microemp. precarios & $2,351^{\star \star \star}$ & $10,490^{\star \star \star}$ & $0,151^{\star \star \star}$ & $1,855^{\star \star \star}$ & $6,391^{\star \star \star}$ & $0,207^{\star \star \star}$ \\
\hline Dummies de rama & & Sí & & & Sí & \\
\hline Dummies de región & & Sí & & & Sí & \\
\hline Constante & $-5,049^{\star \star \star}$ & $0,006^{\star \star \star}$ & & $-2,358^{\star \star \star}$ & $0,095^{\star \star \star}$ & \\
\hline \multicolumn{7}{|l|}{ Estadísticos del modelo } \\
\hline Observaciones & & 24.349 & & & 9.334 & \\
\hline R2 de McFadden & & 0,256 & & & 0,228 & \\
\hline$\%$ global de aciertos & & $84,0 \%$ & & & $87,5 \%$ & \\
\hline
\end{tabular}

Notas: (c) categoría de comparación / significancia de los efectos: ${ }^{\star \star *} p<0,01,{ }^{\star *} p<0,05,{ }^{*} p<0,1$.

Fuente: elaboración propia a partir de microdatos de EPH (INDEC) y ECV (INE). 
conjunto con la calidad de los puestos y el tipo de unidad económica en la que se desempeñan los trabajadores.

En el segundo modelo (tabla 4), se examinan los factores que inciden en la probabilidad de que un trabajador resida en un hogar cuyo ingreso equivalente sea inferior al $60 \%$ de la mediana. Tal como sugieren los antecedentes (García-Espejo y Gutiérrez, 2011; Halleröd et al., 2015; Lohmann y Crettaz, 2018; Tejero, 2018), a diferencia de lo que ocurría con el modelo anterior, aquí se incrementa la relevancia explicativa de las características demográficas y los comportamientos ocupacionales de los integrantes de los hogares. Si bien desaparece el efecto del sexo, en términos de edad los jóvenes son los más expuestos a la probabilidad de residir en un hogar pobre, de igual forma que los que tienen menor nivel de instrucción. La nacionalidad de origen solo conserva peso explicativo en el caso español, donde los extranjeros tienen casi $10 \mathrm{pp}$. más de probabilidad de vivir en hogares pobres que los nativos. A medida que se incrementa el número de menores de 18 años en el hogar, se incrementa la probabilidad de experimentar pobreza. En contraste, se reducen tales chances cuanto se dispone de más miembros ocupados.

Si bien se debilita su fuerza explicativa con respecto al primer modelo, la inserción del trabajador en la estructura económico-ocupacional retiene una importante capacidad explicativa sobre la probabilidad de que resida en un hogar pobre. Los microempresarios y los cuentapropistas no cualificados, junto con los asalariados precarios —en especial, de microestablecimientos-, son los trabajadores más expuestos a la probabilidad de residir en un hogar pobre. Asimismo, en el caso argentino, los trabajadores protegidos de empresas medianas y grandes o del sector público tienen mayor propensión que los grandes empleadores a vivir en un hogar pobre (3,5 y 5 pp., respectivamente).

En suma, en línea con los antecedentes, se han identificado distintos determinantes de la pobreza laboral, tanto del individuo (educación, género u origen migratorio) como de su hogar (comportamientos laborales de los miembros o la composición sociodemográfica), para los casos de Argentina y España (Crettaz, 2013; Lohmann, 2009; Lohmann y Crettaz, 2018). Ahora bien, la estrategia de análisis a través de modelos multivariantes ha permitido resaltar el papel explicativo central de la posición en la estratificación económicoocupacional sobre la probabilidad de experimentar pobreza laboral sea cual sea la definición operativa adoptada. Retomando una perspectiva estructuralista de los procesos de segmentación del mercado laboral, quienes se desempeñan en microunidades o son trabajadores independientes de baja cualificación tienen una mayor propensión a vivir en pobreza, a igualdad de otras condiciones. Ello interactúa con otros atributos del puesto, como la estabilidad o la precariedad. Asimismo, pudo apreciarse que esta propensión reconoce una lógica de estructuración similar en Argentina y en España. En otras palabras, en ambos países son los mismos grupos de trabajadores quienes se encuentran más expuestos a experimentar pobreza, a igualdad de otras condiciones personales o familiares. Este resultado revela la existencia de similitudes en la pauta de desigualdad sociolaboral, más allá de las diferencias estructurales identificadas. 


\section{Conclusiones}

La expansión de formas inestables y precarias de empleo en muchos países desarrollados durante los últimos años y su persistencia en los países periféricos son indicativas de los obstáculos que enfrenta el «trabajo decente» en la actualidad. Estas características de los mercados laborales plantean numerosos desafíos para la cohesión social y la equidad, ya que repercuten sobre distintas dimensiones del bienestar de los trabajadores. En este marco, si en los países periféricos hace varias décadas que se reconoce que la participación en el mercado de trabajo no basta para eludir la pobreza, esta constatación se ha extendido más recientemente también a algunos países centrales. La pobreza laboral pone de manifiesto los límites del empleo como vector de integración social. Si bien la literatura destaca los múltiples determinantes de la pobreza laboral, este artículo se ha interesado por su relación con los procesos de estratificación económico-ocupacional.

Los resultados alcanzados implican aportaciones en dos niveles. En primer lugar, se ha contribuido a caracterizar el perfil de estratificación económicoocupacional en cada país reconociendo sus implicancias para la composición del universo de trabajadores pobres. En segundo lugar, se ha revelado que, más allá de las características individuales o familiares de los trabajadores, la posición económico-ocupacional constituye un factor explicativo central de la probabilidad de experimentar pobreza laboral y que dicha probabilidad se estructura de manera similar en los dos países examinados. De esta forma, el artículo aporta a las investigaciones comparativas sobre la estructuración de las desigualdades sociolaborales entre Europa y América Latina (cfr. López-Roldán y Fachelli, 2019; Semenza y Sartí, 2018) y a aquellos estudios que procuran vincular la pobreza laboral con clivajes ocupacionales (Banyuls y Recio, 2017a; Filandri y Struffolino, 2019; Horemans et al., 2016; Halleröd et al., 2015; Maître et al., 2012; Maurizio, 2018; Salverda, 2018).

Los resultados descriptivos permitieron advertir que las disparidades en el nivel de desarrollo económico y en los marcos institucionales se expresan en diferencias absolutas entre Argentina y España. Argentina tiene una estructura laboral en la que se acentúan los rasgos típicos de su menor nivel de desarrollo económico: hay una significativa mayor presencia de ocupados en microempresas, en actividades por cuenta propia de baja cualificación o en el servicio doméstico a hogares y mayor precariedad que en España. Estas diferencias estructurales se expresan en la incidencia de la pobreza laboral medida desde un enfoque "absoluto»: en el país latinoamericano, casi uno de cada diez trabajadores son pobres o viven en hogares pobres en función de una línea de privaciones que sugiere la insatisfacción de necesidades básicas, mientras que en el país europeo la incidencia del fenómeno es prácticamente marginal.

Por otra parte, el artículo ofreció evidencias robustas acerca del rol fundamental de los procesos de estratificación económico-ocupacional como determinante de la pobreza laboral en Argentina y en España. En este sentido, se constataron similitudes relativas entre los casos estudiados: los grupos económico-ocupacio- 
nales más expuestos a la pobreza son los mismos en ambos países e incluso su probabilidad de ser pobres - a igualdad de otras condiciones individuales o familiares - es muy similar. Esto no significa que el universo de trabajadores pobres sea equivalente en los dos casos, pues, como se indicó, ambos países tienen diferencias relevantes en sus estructuras económico-ocupacionales que se expresan en tal composición. Sin embargo, desde el punto de vista de la estructuración de las desigualdades, la pauta advertida es significativamente parecida en ambos países: los asalariados precarios (en especial, de microempresas) y los microempresarios y cuentapropistas de baja cualificación son los más expuestos a la probabilidad de ser trabajadores pobres o de vivir en hogares pobres. Estos resultados podrían dar cuenta de la organización de las desigualdades laborales en países cuyos sistemas económicos se caracterizan por la existencia de asimetrías productivas entre empresas y ramas y por una extendida precariedad laboral.

Cabe señalar algunas limitaciones de la investigación desarrollada. En primer término, como se indicó, la pobreza remite, en un sentido relevante, a privaciones que condicionan la supervivencia humana. La utilización de medidas relativas de pobreza laboral, si bien favorece la comparación internacional y el análisis de las desigualdades ocupacionales, oscurece este aspecto. En segundo lugar, el análisis transversal y la utilización de una única ventana de observación limitan la comprensión de las dinámicas y las tendencias de la pobreza laboral y sus diferencias entre países. En tercer lugar, es ampliamente reconocido el papel que desempeñan las transferencias de política social en los hogares de trabajadores pobres. Este aspecto no ha sido problematizado aquí y podría iluminar discrepancias entre los casos nacionales analizados.

El análisis comparativo permite ampliar el alcance de los conceptos. Los resultados alcanzados muestran diferencias absolutas entre dos países de desigual nivel de desarrollo que coexisten con formas de estructuración o de organización de la desigualdad que son similares. En este sentido, se abren dos líneas complementarias de investigación. Por una parte, los hallazgos ponen de manifiesto cómo distintas esferas de la diferenciación social — de género, etarias o de composición familiar - se entrelazan en el mercado de trabajo en contextos nacionales disímiles. Ello invita a avanzar hacia enfoques de investigación más integrales, que tematicen las inequidades económico-ocupacionales en conjunto con otros rasgos de los modelos sociales que influyen en el bienestar de los trabajadores y sus hogares. Por otra parte, resultará de interés incorporar nuevos casos nacionales a partir de la «maximización» de sus diferencias, con un doble propósito: por un lado, para evaluar si se profundizan las disparidades absolutas aquí encontradas y, por otro lado, para examinar en qué medida persisten lógicas similares de estructuración de las desigualdades económico-ocupacionales.

\section{Agradecimientos}

Agradezco los comentarios realizados por los participantes de un seminario realizado en la Universitat Autònoma de Barcelona en enero de 2019. También agradezco las recomendaciones de los evaluadores anónimos. 


\section{Financiación}

Este artículo ha sido elaborado en el contexto de la Red INCASI (International Network for Comparative Analysis of Social Inequalities), proyecto que ha recibido financiación del programa Horizon 2020 Research and Innovation Programme bajo el Marie Skłodowska-Curie GA No 691004, coordinado por el Dr. Pedro López-Roldán. El artículo refleja la opinión del autor y la Agencia no es responsable del uso que se pueda hacer de la información que contiene.

\section{Referencias bibliográficas}

Ballesteros, Matías (2018). Promedio de los efectos marginales e interacciones en las regresiones logísticas binarias (INCASI Working Paper Series, 3). Bellaterra: INCASI.

Banyuls, Josep y Recio, Albert (2017a). «Pobreza laboral en España: causas y alternativas de política». Anuario IET. Desigualdades en el Mercado de Trabajo después de la Gran Recesión 4, 135-149.

<https://doi.org/10.5565/rev/aiet.59>

- (2017b). "Labour segmentation and precariousness in Spain: theories and evidence». En: Grimshaw, Damian; Fagan, Colette; Hebson, Gail y Tavora, Isabel (eds.). Making work more equal: A new labour segmentation approach, 124-149. Manchester: Manchester University Press.

Banyuls, Josep; Miguélez, Fausto; Recio, Albert; Cano, Ernest y Lorente, Raúl (2009). "The transformation of the employment system in Spain: Towards a mediterranean neoliberalism?». En: Bosch, Gerhard; LehndorfF, Steffen y Rubery, Jill (eds.). European employment models in flux. A comparison of institutional change in nine European countries, 247-269. Basingstoke: Palgrave Macmillan. <https://doi.org/10.1057/9780230237001_10>

Bertranou, Fabio y Casanova, Luis (2015). Las instituciones laborales y desempeño del mercado de trabajo en Argentina. Buenos Aires: Organización Internacional del Trabajo-Oficina de País de la OIT para Argentina.

Bertranou, Fabio; Casanova, Luis; Jiménez, Maribel y Jiménez, Mónica (2014). «Empleo, calidad del empleo y segmentación laboral en Argentina». Revista de Economía Laboral, 11, 24-64.

Brady, David (2019). "Theories of the Causes of Poverty». Annual Review of Sociology 45 (1), 155-75. <https://doi.org/10.1146/annurev-soc-073018-022550>

Brady, David; Fullerton, Andrew S.; Moren Cross, Jennifer (2010). «More Than Just Nickels and Dimes: A Cross-National Analysis of Working Poverty in Affluent Democracies». Social Problems, 57 (4), 559-85. $<$ https://doi.org/10.1525/sp.2010.57.4.559>

Brady, David; Baker, Regina y Finnigan, Ryan (2013). "When Unionization Disappears: State-Level Unionization and Working Poverty in the United States». American Sociological Review, 78 (5), 872-96. <https://doi.org/10.1177/0003122413501859>

CAÏs, Jordi (1997). Metodología del Análisis Comparativo. Madrid: CIS. 
Chávez Molina, Eduardo; Solís, Patricio y Cobos, Daniel (2019). «Class Structure, Labor Market Heterogeneity and Living Conditions in Latin America». Latin American Research Review, 54 (4), 854-876. $<$ https://doi.org/10.25222/larr.442>

CEPAL (Comisión Económica para América Latina) (2019). Panorama Social de América Latina. Santiago de Chile: Naciones Unidas, CEPAL. <https://doi.org/10.2307/j.ctv550d07.6>

Comisión Europea (2019). European Economic Forecast (European Economy Institutional Papers, 108). Luxemburgo.

$<$ https://doi.org/10.2765/3931>

Cortés, Fernando (2000). «La metamorfosis de los marginales: la polémica sobre el sector informal en América Latina». En: Garza Toledo, Enrique de la (ed.). Tratado Latinoamericano de Sociología del Trabajo, 592-618. México DF: El Colegio de México, FLACSO, UNAM, Fondo de Cultura Económica.

Crettaz, Eric (2013). «A State-of-the-Art Review of Working Poverty in Advanced Economies: Theoretical Models, Measurement Issues and Risk Groups». Journal of European Social Policy, 23 (4), 347-62. <https://doi.org/10.1177/0958928713507470>

Doeringer, Peter y Piore, Michael (1971). Internal Labor Markets and Manpower Analysis. Lexington DC: Heath \& Co.

DonZa, Eduardo (2019). Heterogeneidad y fragmentación del mercado de trabajo (20102018). Buenos Aires: EDUCA.

Feres, Juan Carlos y Mancero, Xavier (2001). Enfoques para la medición de la pobreza. Breve revisión de la literatura (Serie Estudios Estadísticos y Prospectivos). Santiago de Chile: CEPAL.

FERnÁndez-Huerga, Eduardo (2010). «La teoría de la segmentación del mercado de trabajo: enfoques, situación actual y perspectivas de futuro». Investigación Económica, 69 (273), 115-150.

Ferreira, Francisco; Messina, Julián; Rigolini, Jamele; López-Calva, Luis; Lugo, Maria y VAKIs, Renos (2012). Economic Mobility and the Rise of the Latin American Middle Class. The World Bank. <https://doi.org/10.1596/978-0-8213-9634-6>

Filandri, Marianna y Struffolino, Emanuela (2019). «Individual and household in-work poverty in Europe: understanding the role of labor market characteristics». European Societies, 21 (1), 130-57. <https://doi.org/10.1080/14616696.2018.1536800>

Fraser, Neil; Gutiérrez, Rodolfo y Peña-Casas, Ramón (2011). «Introduction». En: Fraser, Neil; Gutiérrez, Rodolfo y Peña-Casas, Ramón (eds.). Working Poverty in Europe, 1-14. Nueva York: Palgrave Macmillan. <https://doi.org/10.1057/9780230307599>

García-Espejo, Isabel y Gutiérrez, Rodolfo (2011). «Spain: Persisting Inequalities in a Growing Employment Context». En: Fraser, Neil; Gutiérrez, Rodolfo y PeÑa-Casas, Ramón (eds.). Working Poverty in Europe, 133-154. Nueva York: Palgrave Macmillan. <https://doi.org/10.1111/j.1467-9957.2011.02230.x>

Gasparini, Leonardo y Tornarolli, Leopoldo (2009). «Labor Informality in Latin America and the Caribbean: Patterns and Trends from Household Survey Microdata». Desarrollo y Sociedad, 63, 13-80.

Grimshaw, Damian; Fagan, Colette; Hebson, Gail y Tavora, Isabel (2017). «A New Labour Market Segmentation Approach for Analysing Inequalities: Introduction 
and Overview». En: Grimshaw, Damian; Fagan, Colette; Hebson, Gail y TavORA, Isabel (eds.). Making work more equal: A new labour segmentation approach, 124-149. Manchester: Manchester University Press.

Halleröd, Björn; Ekbrand, Hans y Bengtsson, Mattias (2015). «In-Work Poverty and Labour Market Trajectories: Poverty Risks among the Working Population in 22 European Countries». Journal of European Social Policy, 25 (5), 473-88. <https://doi.org/10.1177/0958928715608794>

Horemans, Jeroen; Marx, Ive y Nolan, Brian (2016). "Hanging in, but only just: Part-time employment and in-work poverty throughout the crisis». IZA Journal of European Labor Studies 5 (5), 1-19. <https://doi.org/10.1186/s40174-016-0053-6>

Hussmans, Ralph (2004). Measuring the Informal Economy: From Employment in the Informal Sector to Informal Employment (Documento de Trabajo, 53). Ginebra: Organización Internacional del Trabajo.

ILO (International Labour Office) (1999). Memoria del Director General. Trabajo Decente. Informe 87 (ed. ILO). Ginebra. Recuperado de <https://www.ilo.org/ public/spanish/standards/relm/ilc/ilc87/rep-i.htm>.

- (2018). Panorama Laboral 2018. América Latina y El Caribe. Lima: Organización Internacional del Trabajo, Oficina Regional para América Latina y el Caribe. Recuperado de <https:/www.ilo.org/wcmsp5/groups/public/---americas/---rolima/documents/pub lication/wcms_654969.pdf>.

- (2019). World Employment and Social Outlook: Trends 2019. Ginebra: International Labour Organization. Recuperado de <https://www.ilo.org/wcmsp5/groups/ public/dgreports/dcomm/publ/documents/publication/wcms_670542.pdf>.

Jelin, Elizabeth (2010). Pan y afectos. La transformación de las familias. Buenos Aires: Fondo de Cultura Económica.

Infante, Ricardo (2011). América Latina en el «umbral del desarrollo». Un ejercicio de convergencia productiva (Proyecto Desarrollo inclusivo Documento de Trabajo, 14). Santiago de Chile: CEPAL. Recuperado de <https://repositorio.cepal.org/ bitstream/handle/11362/35447/1/Infanteumbraldesarrollo_es.pdf>.

Lohmann, Henning (2009). "Welfare States, Labour Market Institutions and the Working Poor: A Comparative Analysis of 20 European Countries». European Sociological Review, 25 (4), 489-504. <https://doi.org/10.1093/esr/jcn064>

- (2018). "The Concept and Measurement of In-Work Poverty». En: Lohmann, Henning y Marx, Ive (eds.). Handbook on In-Work Poverty, 7-25. Cheltenham: Edward Elgar. <https://doi.org/10.4337/9781784715632>

Lohmann, Henning y Crettaz, Eric (2018). "Explaining Cross-Country Differences in in-Work Poverty». En: Lohmann, Henning y Marx, Ive (eds.). Handbook on In-Work Poverty, 50-69. Cheltenham: Edward Elgar.

López-Roldán, Pedro y Fachelli, Sandra (2019). «Segmentación del empleo y apreciación de la educación en un modelo productivo anclado. Análisis comparativo entre España y Argentina». Papers. Revista de Sociologia, 104 (2), 159-202. $<$ https://doi.org/10.5565/rev/papers.2571>

López-Roldán, Pedro; Miguélez, Faustino; Lope, Andreu y Coller, Xavier (1998). "La segmentación laboral: hacia una tipología del ámbito productivo». Papers. Revista de Sociologia, 55, 45-77. <https://doi.org/10.5565/rev/papers.1932> 
Maître, Bertrand; Nolan, Brian y Whelan, Christopher (2012). «Low Pay, In-Work Poverty And Economic Vulnerability: A Comparative Analysis Using EU-SILC». Manchester School, 80 (1), 99-116. <https://doi.org/10.1111/j.1467-9957.2011.02230.x>

Maurizio, Roxana (2018). «In-Work Poverty in Latin America: Prevalence, Driving Forces and Trends». En: Lohmann, Henning y Marx, Ive (eds.). Handbook on In-Work Poverty, 347-364. Cheltenham: Edward Elgar.

Mood, Carina (2010). «Logistic Regression: Why We Cannot Do What We Think We Can Do, And What We Can Do About It». European Sociological Review, 26 (1), 67-82. <https://doi.org/10.1093/esr/jcp006>

NefFa, Julio César (2008). «Las teorías de la segmentación de los mercados de trabajo». En: Eymard-Duvernay, Françoise y Neffa, Julio César (eds.). Teorías económicas sobre el mercado de trabajo. III. Análisis institucionalistas, 139-206. Buenos Aires: Fondo de Cultura Económica-CEIL-PIETTE.

Nohlen, Dieter y Sturm, Roland (1982). «La heterogeneidad estructural como concepto básico de la Teoría de Desarrollo». Revista de Estudios Políticos (28), 45-74.

Osterman, Paul (1984). Internal Labor Markets. Cambridge: MIT Press.

PAZ, Jorge (2013). «Segmentación del mercado de trabajo en la Argentina». Desarrollo y Sociedad (72), 105-156. <https://doi.org/10.13043/DYS.72.3>

Peña-Casas, Ramón y Ghailani, Dalila (2011). «Towards Individualizing Gender In-Work Poverty Risks» En: Fraser, Neil; Gutiérrez, Rodolfo y Peña-Casas, Ramón (eds.). Working Poverty in Europe, 202-231. Nueva York: Palgrave Macmillan. <https://doi.org/10.1111/j.1467-9957.2011.02230.x>

Pérez-Sáinz, Juan Pablo y Mora-Salas, Minor (2006). «Exclusión social, desigualdades y excedente laboral. Reflexiones analíticas sobre América Latina». Revista Mexicana de Sociología, 68 (3), 431-65.

Pinto, Aníbal (1970). «Naturaleza e implicaciones de la "heterogeneidad estructural" de la América Latina». El Trimestre Económico, 37 (145), 83-100.

Piore, Michael (1972). Notes For A Theory Of Labor Market Stratification (Working Paper Department of Economics, 95). Cambridge, Massachusetts: MIT Press.

Piovani, Juan y KrawczyK, Nora (2017). "Los estudios comparativos: algunas notas históricas, epistemológicas y metodológicas». Educação \& Realidade, 42 (3), 821-840. <https://doi.org/10.1590/2175-623667609>

Ponthieux, Sophie (2013). «Income pooling and equal sharing within the household. What can we learn from the 2010 EU-SILC module?». Eurostat Methodologies \& Working Papers. Luxemburgo: European Comission. <https://doi.org/10.2785/21993>

Poy, Santiago (2017). «Heterogeneidad de la estructura ocupacional y segmentación del mercado de trabajo. Gran Buenos Aires, 1974-2014». Trabajo y Sociedad, 29, 353-376.

PREALC (Programa Regional de Empleo para América Latina y el Caribe) (1978). Sector Informal. Funcionamiento y Politicas. Santiago de Chile: OIT.

Recio, Albert (1991). "La segmentación del mercado de trabajo en España». En: Miguélez, Fausto y Prieto, Carlos (eds.). Las relaciones laborales en España, 97-115. Madrid: Siglo XXI. 
ReIch, Michael; Gordon, David y Edwards, Richard (1973). «Dual Labor Markets: A Theory of Labor Market Segmentation». American Economic Review, 63, 359-365.

Rodríguez, Octavio. (2001). «Prebisch: actualidad de sus ideas básicas». Revista de la CEPAL, 75, 41-52. <https://doi.org/10.18356/63e7452f-es>

Rubery, Jill (2015). Re-regulating for Inclusive Labour Markets (Conditions of Work and Employment Series, 65). Ginebra: International Labour Office.

Salverda, Wiemer (2018). «Low Earnings and Their Drivers in Relation to In-Work Poverty». En: Lohmann, Henning y Marx, Ive (eds.). Handbook on In-Work Poverty, 26-49. Cheltenham: Edward Elgar.

Salvia, Agustín y Vera, Julieta (2013). «Heterogeneidad estructural y distribución de los ingresos familiares en el Gran Buenos Aires (1992-2010)». Desarrollo Económico, 52 (207), 427-462.

Salvia, Agustín; Robles, Ramiro y Fachal, María (2018). «Estructura sectorial del empleo, nivel educativo de la fuerza de trabajo y diferenciales de ingresos laborales en la Argentina (1992-2014)». Cuadernos de Relaciones Laborales, 36 (2), 325-354. <https://doi.org/10.5209/CRLA.60700>

Semenza, Renata y SARTI, Simone (2018). «Labour market segmentation: The economic condition of self-employed professionals in Italy and Argentina». Papers. Revista de Sociologia, 104 (2), 203-23. <https://doi.org/10.5565/rev/papers.2578>

Spicker, Paul (2007). «Definitions of Poverty: Twelve Clusters of Meaning». En: Spicker, Paul; Álvarez Leguizamón, Sonia y Gordon, David (eds.). Poverty. An International Glossary, 229-243. Nueva York: CROP-ISS Zed Books.

Tejero Pérez, Aroa (2018). «Pobreza Laboral en España. Una Perspectiva Dinámica». Revista Internacional de Sociología, 76 (2), 2-18. <https://doi.org/10.3989/ris.2018.76.2.16.54>

Thiede, Brian; Sanders, Scott y Lichter, Daniel (2018). "Demographic Drivers of In-Work Poverty». En: Lohmann, Henning y Marx, Ive (eds.). Handbook on In-Work Poverty, 109-123. Cheltenham: Edward Elgar.

TOKMAN, Víctor (2006). Inserción laboral, mercados de trabajo y protección social (Serie Financiamiento del Desarrollo, 170). Santiago de Chile: CEPAL.

Vera, Julieta y Poy, Santiago (2017). «Mercado laboral, políticas sociales y desigualdad: cambios recientes en perspectiva histórica. Gran Buenos Aires (1974-2014)». Economía UNAM, 14 (42), 3-23.

Verd, Joan Miquel y López-Andreu, Martí (2016). «Crisis del empleo y polarización de las trayectorias laborales. El caso de los adultos jóvenes en Cataluña». Papers. Revista de Sociologia, 101 (1), 5-30.

<https://doi.org/10.5565/rev/papers.2167> 